\section{Revista}

A Cor

das Letras

\title{
Uma análise sociolinguística do objeto nulo no corpus do PEPP
}

\author{
A sociolinguistic analysis of the null object in the PEPP corpus
}

\author{
Jilvan Evangelista da Silva* \\ Universidade Federal da Babia \\ Salvador, Bahia, Brasil \\ Marcela Moura Torres Paim** \\ Universidade Federal da Babia \\ Salvador, Bahia, Brasil
}

Resumo: Este trabalho tem como objetivo apresentar uma análise sociolinguística do objeto nulo no corpus do Programa de Estudos sobre o Português Popular Falado de Salvador - PEPP. Diferentemente das variáveis linguísticas, que os gerativistas propõem-se a estudar em diferentes línguas do mundo, o foco aqui é verificar como as variáveis sociais comportam-se diante desse fenômeno, baseando-se nos pressupostos da sociolinguística variacionista. Além dessas, selecionamos a variável linguística animacidade para verificar se este é um traço distintivo no português brasileiro. Esse fenômeno tem um caráter bastante relevante no português brasileiro, pois é uma língua que permite o preenchimento da posição de objeto, bem como seu apagamento, estratégia utilizada para escapar do julgamento linguístico da sociedade, ou seja, não utilizar uma forma estigmatizada, que é o caso do preenchimento com um pronome lexical (cf. CÔRREA, 1992), mas não o clítico, que só é realizado em contextos de muita monitoração linguística. É importante salientar que é necessário fazer a continuação do estudo para chegar a dados mais conclusivos.

Palavras-Chaves: Categoria vazia. Objeto nulo. Animacidade. Variáveis sociais. Sociolinguística.

Abstract: This paper aims to present a sociolinguistic analysis of the null object in the Programa de Estudos sobre o Português Popular Falado de Salvador - PEPP (Program of Studies on Popular spoken Portuguese in Salvador). Different from linguistic variables, which generative linguistics studied in different languages around the world, our goal here is to observe how social variables behavior in the light of this phenomenon, based on Variacionist Sociolinguistics background. Furthermore, we added the linguistic variable animacy to verify if this trace is distinctive in Brazilian Portuguese. This phenomenon has a relevant disposition in Brazilian Portuguese, because this language allows the filling of accusative position, and its deletion, a strategy used to scape from linguistic judment of the society, in other words, using a form not stigmatized, which is the use of a lexical pronoun in this position (cf. CÔRREA, 1992), not a clitic, which is used in monitoring linguistic context. It is important to point ou that is necessary the improvement of this study to reach more conclusive data.

Keywords: Empty category. Null Object. Animacy. Social Variables. Sociolinguistics.

* Estudante de mestrado do PPGLINC/UFBA. E-mail: silvaje1991@gmail.com.

** Doutora em Letras e Linguística (UFBA). Professora da Universidade Federal da Bahia. Email: marcelamtpaim@yahoo.com.br. 


\section{INTRODUÇÃO}

A sociolinguística é uma área que compreende a língua como algo heterogêneo e sistemático. Segundo Tarallo (1986), podem ser chamados de sociolinguistas todos aqueles que entendem por língua um meio de comunicação, de informação e de expressão entre os indivíduos da espécie humana. A proposta da sociolinguística é unir fatores linguísticos e sociais, o que não foi feito pelos estruturalistas ou pelos gerativistas, com a finalidade de verificar como os fatores sociais, tais como sexo, idade, nível de instrução, etc., influenciam no uso diário da língua.

Com base nos pressupostos da sociolinguística, propõe-se uma análise da categoria vazia, objeto nulo, que é um fenômeno linguístico bastante estudado nas línguas do mundo, pelos gerativistas (RAPOSO, 1986, GALVES, 1989), porque a possibilidade do apagamento dessas categorias tem implicação sintática, semântica e discursiva. Para este trabalho, tomam-se, como ponto de partida, os trabalhos variacionistas de Duarte (1986) e Corrêa (1992), para mostrar a importância das variáveis sociais nesse fenômeno.

Uma língua como o inglês não permite o apagamento dessas categorias devido à perda morfológica drástica em sua história. Já o chinês, que é uma língua de orientação discursiva, apaga tanto a posição de sujeito quanto de objeto, pois o tópico controla esse apagamento, que é recuperado discursivamente. Já o português brasileiro (doravante PB) perdeu pronomes durante seu percurso histórico, o que acarretou em uma perda morfológica verbal (cf. ROBERTS, 2009), trazendo consequências para a tipologia dessa língua.

Devido ao caráter híbrido do $\mathrm{PB}$, quanto à possibilidade de preenchimento/não preenchimento da posição de objeto, é necessário verificar seu comportamento diante das variáveis sociais, pois o percurso ocorrido para a perda pronominal e, posteriormente, morfológica tem relação com mudanças sociais. As escolhas que os falantes fazem não são aleatórias e isso pode ser verificado ao observar as variáveis sociais, que interferem no uso da língua, fazendo com que os falantes se utilizem de diferentes escolhas no ato comunicativo (DUARTE, 1986).

Além desta introdução, este artigo contém mais quatro seções. Na seção 2, será exposto o que se propõe na literatura sobre o objeto nulo; na seção seguinte, será apresentada a metodologia utilizada; na seção 4, serão apresentadas as análises e interpretações dos dados obtidos; e, por fim, serão traçadas as considerações finais.

\section{O OBJETO NULO NO PORTUGUÊS BRASILEIRO}

Neste trabalho, assume-se que o objeto nulo é um elemento não pronunciado no ato comunicativo, mas que tem sua significação recuperada discursivamente, isso porque o PB é uma língua do tipo tópico-comentário, ou seja, o tópico, que é o elemento mais 
alto, controla a categoria vazia, permitindo recuperar o significado do elemento apagado. Vejamos o exemplo abaixo:

DOC: Ah, sua mãe praticamente mandava DINHEIRO ... (superp) pra manter vocês... INQ19: Ela dava porque minha mãe (superp), eh, minha mãe ficou encostada, minha mãe trabalhava, ficou encostada nessa firma, hoje em dia que ela é aposentada e trabalha em prédio, então ... ela, ele, ele, ela pegava e dava esse dinheiro todo mês a ela.

Nesse exemplo, há uma lacuna na posição de objeto, que é recuperado porque o sintagma nominal - dinheiro - já foi mencionado, ou seja, pode-se recuperar esse elemento mais alto discursivamente. Línguas como o inglês ou o português europeu (doravante PE) não permitem essa lacuna, pois têm um direcionamento discursivo diferente do $\mathrm{PB}$. $\mathrm{O}$ inglês preencheria a lacuna mencionada no exemplo acima com o pronome it. $\mathrm{O} P E$ preencheria essa lacuna com o clítico acusativo $o$, porque é uma língua que preenche a posição de objeto e permite o apagamento da posição de sujeito.

$\mathrm{Na}$ literatura acerca da identificação dessas categorias vazias, que não é consensual (cf. VALVERDE-HÜBNER, 2012), pois é possível analisá-las como objeto nulo ou elipse de $\mathrm{VP}^{1}$. O objeto nulo ocorre quando há o apagamento apenas do sintagma nominal, já a elipse de VP, ocorre quando todo o sintagma nominal é apagado. Vejamos os exemplos abaixo:

a) John loves cake and Lilly does too $^{2}$.

b) João descascou a banana, mas Pedro não descascou

c) João descascou a banana, mas Pedro não comeu

Em (a), temos um exemplo do inglês para a elipse de VP, pois o verbo não é repetido na oração coordenada 2 , apenas o auxiliar é realizado, o que revela que houve a elipse de todo o sintagma verbal. No PB, segundo Matos (1992), é preciso haver identidade entre os verbos para que ocorra elipse de VP no português, ou seja, em (b), temos uma elipse de VP, já que há identidade entre os verbos, inclusive é possível apagar o verbo da oração coordenada 2 . Em (c), temos um objeto nulo, já que não há identidade entre os verbos.

Para aprofundar essa distinção nos dados do PB, contrastemos os dados a seguir, retirados de Silva (2009, p. 17), para ampliar ainda mais essa discussão, visto que o fato de os verbos serem iguais não configura um apagamento de VP.

(d) Luís prometeu levar sua namorada ao cinema, mas não levou

(e) João trouxe os presentes de seus filhos, mas não distribuiu

(f) Luís prometeu levar sua namorada ao cinema, mas levou ao teatro.

Silva (2009) argumenta que em (d) - exemplo 1(a) no original - a raiz do verbo nas duas orações é idêntica e, além disso, não só o sintagma nominal foi apagado, mas também o sintagma preposicionado, ao cinema, configurando um apagamento de todo o sintagma verbal. Em (e), os verbos são diferentes, o que coloca a lacuna na posição de

${ }^{1}$ Verbal Phrase $=$ Sintagma verbal.

2 John ama bolo e Lilly também. 
objeto direto como um objeto nulo, posto que não é o VP que está apagado, mas sim o sintagma nominal, os presentes de seus filhos. Já em (f), embora os verbos sejam iguais, o sintagma preposicionado, ao teatro, foi realizado, confirmando a existência de um objeto nulo, diferentemente do exemplo em (d), em que todos os sintagmas da estrutura verbal são apagadas da oração 2 .

\section{METODOLOGIA}

A análise assumida neste artigo pauta-se em duas análises complementares. A primeira é a proposta de Matos (1992), como foi explicada acima. A segunda análise é a proposta de Cyrino (2000) ao assumir que "a categoria vazia do objeto nulo no português brasileiro é uma elipse de $\mathrm{NP}^{3}$, que deverá ser reconstruída em FL [Forma Lógica] e sofrer elipse em FF [Forma Fonética]", ou seja, há uma elipse do sintagma nominal na posição de objeto, essa lacuna vai ser recuperada semanticamente na forma lógica ${ }^{4}$ e a elipse só ocorre na fala por causa da forma fonética ${ }^{5}$. As propostas são complementares porque a primeira mostra uma forma de identificá-las e a segunda explica como isso ocorre na perspectiva gerativista.

Para a análise dos dados, a metodologia adotada foi a da sociolinguística quantitativa para verificar o desenvolvimento do objeto nulo na fala de Salvador. Para isso, foi selecionado o corpus do PEPP - Programa de Estudos sobre o Português Popular Falado de Salvador, que se iniciou com a Profa. Myrian Barbosa da Silva, sendo coordenado pela Profa. Norma da Silva Lopes, na UNEB, com a ajuda de Constância Maria Borges de Souza e Emília Helena Portella Monteiro de Souza, doutorandas da Universidade Federal da Bahia no período de formação do corpus (cf. LOPES, SOUZA, E.; SOUZA, C., 2009).

O objetivo do projeto foi gravar entrevistas em contexto de fala, o menos monitorado possível, para trazer dados relevantes sobre a fala de soteropolitanos, o que de fato interessa para a análise aqui desenvolvida, e suprir a falta de dados sobre o português falado pelos não universitários. Assim, o PEPP tem como níveis definidos de escolaridade o Fundamental e o Médio, totalizando 11 anos de estudo. As entrevistas foram gravadas em 1998 e 1999 com temas relacionados à educação do passado e a do presente, os castigos e as relações de pais e filhos, justamente para que o entrevistado, ao lembrar-se de fatos do passado, monitore-se cada vez menos.

As entrevistas foram gravadas em diferentes bairros de Salvador. Para o nível fundamental, foram realizadas entrevistas em bairros como: Mata Escura, São Caetano, Tancredo Neves, Itapagipe, Sussuruana e Periperi. Para o nível médio, os bairros selecionados foram: Plataforma, Paripe, Mussurunga, Saboeiro, Massaranduba, Cabula VI, Barra e Caminho das Árvores.

\footnotetext{
3 Sintagma nominal

4 Área de interface conceitual-intensional responsável pelos traços semânticos da língua.

5 Área de interface sensório-motora responsável pelos traços fonéticos e fonológicos da língua.
} 
O PEPP tem como delimitação 4 (quatro) faixas etárias, como pode ser visto no quadro abaixo:

\begin{tabular}{|c|c|c|c|}
\hline Faixa I & Faixa II & Faixa III & Faixa IV \\
\hline 15 a 24 anos & 25 a 35 anos & 45 a 55 anos & $\begin{array}{c}65 \text { anos em } \\
\text { diante }\end{array}$ \\
\hline
\end{tabular}

Foram selecionadas três das quatro faixas propostas, I, II e IV, sendo quatro falantes para cada faixa, dois de nível fundamental e dois de nível médio.

As variáveis selecionadas para o estudo do objeto nulo nesse corpus foram três: (i) a variável diageracional, pois, seguindo os estudos diacrônicos de Cyrino (2006), esperase que o uso do objeto nulo seja um tipo de estratégia cada vez mais utilizado, pois o uso das categorias vazias no PB tem uma tendência crescente; (ii) a variável diastrática, que, como observa Corrêa (1992), a relutância em se usar o clítico na fala é comparável à de se usar o pronome pleno na escrita culta. A fala dos mais escolarizados admite, embora com restrição, o pronome lexical, assim como, de modo mais liberal, o objeto nulo; e (iii) com relação à variável diassexual, esperando-se que o uso do objeto nulo não seja tão destoante entre homens e mulheres, visto que as relações sociais de ambos não são estanques como antigamente. Além das variáveis sociais, foi levada em consideração uma variável linguística - a animacidade, em razão de esse traço ser relevante em dados de línguas que permitem objeto nulo - ON. Com o quadro abaixo mostra, é possível ter uma visão geral do recorte feito do corpus do PEPP para a análise do ON no PB. Foram selecionados 12 inquéritos e distribuídos da seguinte forma:

\begin{tabular}{|c|c|c|c|c|c|}
\hline \multicolumn{2}{|c|}{ FAIXA ETÁRIA } & \multicolumn{2}{c|}{ ESCOLARIDADE } & \multicolumn{2}{c|}{ SEXO } \\
\cline { 3 - 6 } & Fundamental & Médio & Homem & Mulher \\
\hline I & 15 a 24 anos & 2 (inq. 18 e 44) & 2 (inq. 20 e 12) & 2 & 2 \\
\hline II & 25 a 35 anos & 2 (inq. 40 e 19) & 2 (inq. 13 e 23) & 2 & 2 \\
\hline IV & 65 em diante & 2 (inq. 34 e 01) & 2 (inq. 14 e 41) & 2 & 2 \\
\hline
\end{tabular}

O fato de a faixa 3 (três) não ter sido analisada não tem motivos qualitativos, mas sim devido ao tempo limitado, embora seja interessante um outro estudo que inclua tal faixa, podendo revelar dados interessantes. Outro aspecto relevante de menção é o não uso de programas estatísticos como o VARBRUL, que poderia revelar outros dados também interessantes para a análise, contudo não houve tempo hábil para sua realização.

Para a análise do objeto nulo, foram desconsiderados os objetos nulos oracionais, como as orações subordinadas substantivas/relativas objetivas diretas, pois como foi mencionado na seção anterior, o objetivo era mapear apenas as elipses de NP. Dessa forma, espera-se que outros estudos deem conta de análises desse tipo, que também apresentam relevância. 


\section{ANÁLISE E INTERPRETAÇÃO DOS DADOS}

Nesta seção, apresentam-se as análises das variáveis linguísticas e sociais selecionadas, sendo elas: animacidade - como a variável linguística; e as três variáveis sociais - diageracional, diastrática e diassexual. Além disso, mostra-se a interpretação desses dados, ou seja, como podemos entender os dados analisados para uma proposta do fenômeno na fala dos soteropolitanos.

\subsection{VARIÁVEL LINGUÍSTICA: ANIMACIDADE}

O traço de animacidade é bastante discutido na literatura sobre o objeto nulo, pois apenas os dados com o traço [- animado] pareciam liberar o objeto nulo, conforme apontado por Duarte (1986). No entanto, a mesma autora argumenta que esse traço não é distintivo no $\mathrm{PB}$, dado que esta língua licencia tanto o ON correferencial a sintagmas com o traço [- animado], quanto com o traço [ + animado], como podem ser observados abaixo:

\section{INQ12_HOMEM_FUNDAMENTAL_F1}

DOC: E de chutar lata que você não explicou como é?

18: Ah, a gente enche A LATA DE PAPEL, aí bota um, um arame, fura os dois lados, bota e sai pela rua chutando A LATA DE PAPEL, fazendo zoada meia noite, uma hora da manhã.

DOC: Hum...

18: Pra não deixar O PESSOAL dormir muito cedo, que lá em Nazaré é um bairro muito calmo, só mora senhor de idade, senhora, aí a gente aí pra não deixar dormir muito cedo aí a gente ficava abusando O PESSOAL.

DOC: Hum, e eles não reclamavam não?

No exemplo retirado do inquérito 18, temos um exemplo de correferência com o traço [animado], em que o entrevistado fala de uma lata de papel e deixa uma lacuna vazia em "[...] sai pela rua chutando [...]"; e um tipo de correferência com o traço [+ animado], em que também destacamos a posição vazia com - o pessoal -, no trecho em "[...] aí a gente ficava abusando ".

A não distinguibilidade do traço de animacidade no corpus do PEPP pode ser confirmada nos dados analisados da variável linguística do PEPP, consoante a tabela 1:

\begin{tabular}{|c|c|c|}
\hline Traço de animacidade & Ocorrências & Porcentagem \\
\hline + animado & 92 & $36 \%$ \\
\hline - animado & 163 & $64 \%$ \\
\hline
\end{tabular}

Tabela 1: Dados relativos à variável linguística: animacidade 
A tabela 1 mostra que o ON com o traço semântico [+ animado] é produtivo no PB, conforme apontou Duarte (1986), totalizando 36\% (92 ocorrências) dos dados. Isso mostra que, diferentemente de análises baseadas em línguas como o PE, pode-se concluir que o traço de animacidade é relevante no PE, que revela preferência apenas pelo traço [animado] nas poucas ocorrências de $\mathrm{ON}$, mas não no $\mathrm{PB}$, que apresenta uma variação estável no licenciamento dessa estratégia linguística. Essa variação fica clara no gráfico 1:

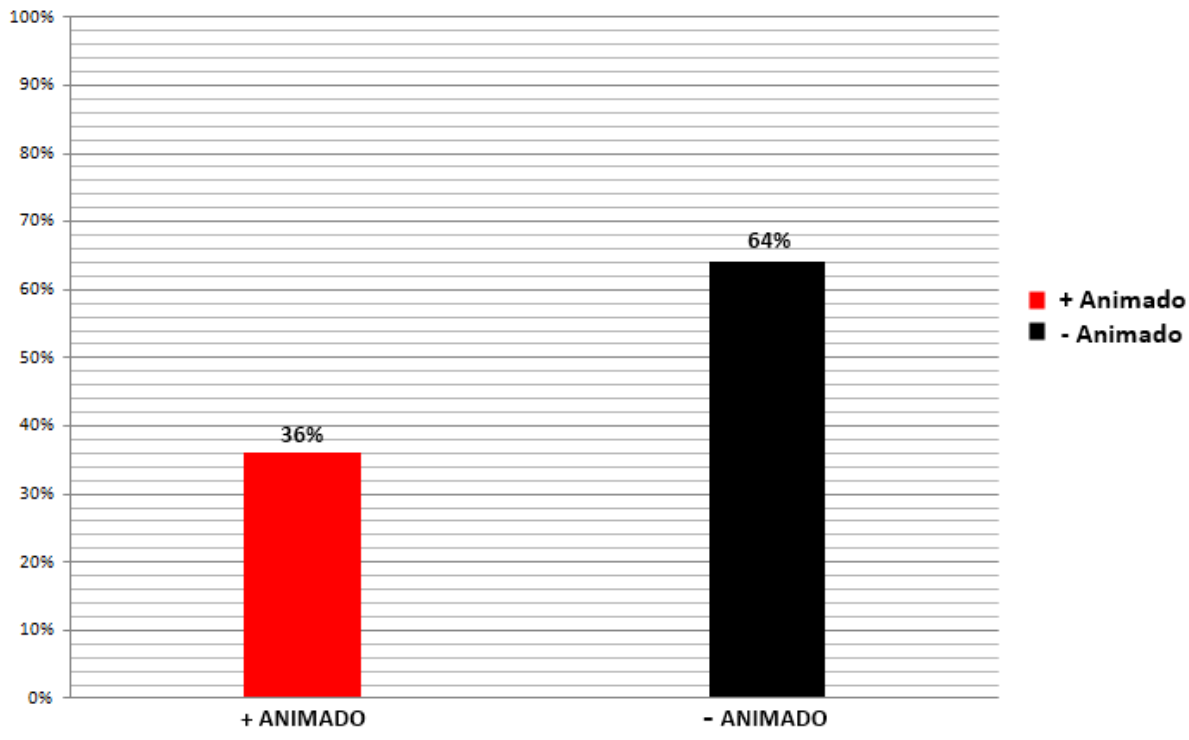

Gráfico 1: Dados relativos à variável diageracional

\subsection{VARIÁVEL DIAGERACIONAL}

Segundo Moreno-Fernández (1998), a idade dos falantes, como apontado desde a Dialetologia, é um dos fatores sociais que, com maior força e clareza, podem determinar os usos linguísticos de uma comunidade de fala. Isso mostra que a variável diageracional permite-nos perceber como cada faixa se comporta diante de um fenômeno linguístico, nesse caso o objeto nulo.

Para a análise inicial, foram selecionadas as faixa II e IV, com o objetivo de verificar o comportamento do objeto nulo na fala dos jovens adultos que estão inseridos no ambiente de trabalho e dos mais velhos. No entanto, os dados obtidos revelaram um resultado que não estava de acordo com trabalhos diacrônicos de Cyrino (2006), em razão de que se dava a entender que estava acontecendo mais preenchimento na faixa IV. Dessa forma, optou-se por incluir a faixa I para comparar com os dados iniciais e verificar se também havia um decréscimo da categoria vazia. Em suma, foram selecionadas 3 faixas etárias, sendo descartada apenas a faixa III, pelos motivos já mencionados. 
O levantamento dos dados de objeto nulo no corpus do PEPP obteve um total de 255 ocorrências e uma distribuição entre as faixas, conforme a tabela 2 :

\begin{tabular}{|c|c|c|}
\hline Faixas & Ocorrências & Porcentagem \\
\hline I (15-24 anos) & $113 / 255$ & $44 \%$ \\
\hline II (25-25 anos) & $66 / 255$ & $26 \%$ \\
\hline IV (65 anos em diante) & $76 / 255$ & $30 \%$ \\
\hline
\end{tabular}

Tabela 2: Dados relativos à variável diageracional

Os dados mostram que as faixas II e IV aproximam-se quanto ao uso do objeto nulo, enquanto que a faixa I, a dos mais jovens, utiliza mais essa estratégia. Isso já era esperado, pois os trabalhos diacrônicos mencionados apontam para esse favorecimento do ON. O gráfico 2 deixa claro o comportamento dessas três faixas:

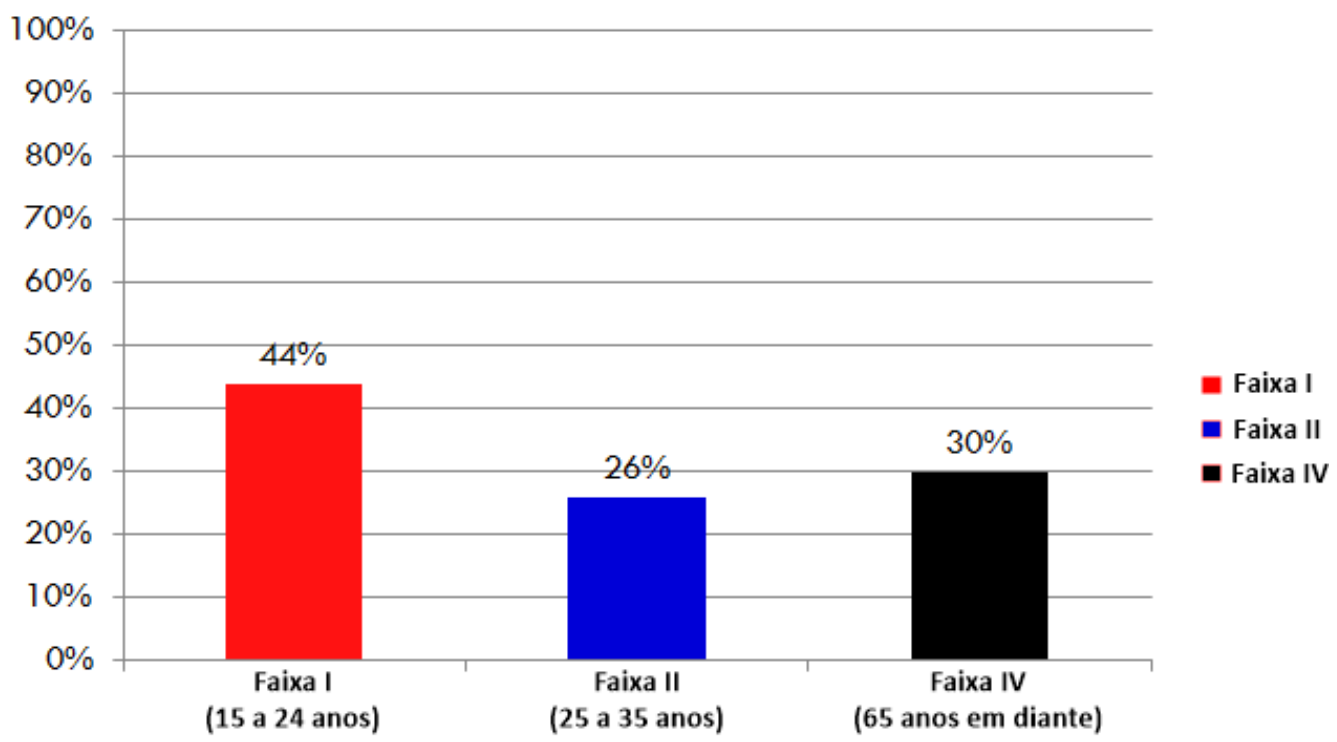

Gráfico 2: Dados relativos à variável diageracional

Um fato curioso é o de a faixa II ser a que apresentou menor ocorrência, visto que é a faixa em que se encontram falantes inseridos no mercado de trabalho, que exige um uso da variedade culta da língua portuguesa. A língua culta estabelece que a posição de objeto, quando realizado, deve ser com os clíticos acusativos $(o, a$,$) , que não são$ característicos do PB. Sendo assim, essa posição só pode ser preenchida por pronome lexical (ele, ela), que, no entanto, está sujeito à estigmatização social, por ser de baixo prestígio.

Um questionamento que pode ser feito com relação ao grande número de ocorrências da faixa I está relacionado às idades estabelecidas para tal faixa, pois entre 15- 
18 anos os falantes ainda não são tão pressionados socialmente para buscar estratégias como a o uso do $\mathrm{ON}$ - para não serem estigmatizados. Em contraparte, os falantes de 19-24 anos já sofrem essa pressão social, pois é o período de ingresso no mercado de trabalho ou a preparação para tal.

\subsection{VARIÁVEL DIASTRÁTICA}

O nível de instrução de um falante interfere nas escolhas linguísticas, justamente por estarem conscientes do poder da língua, tanto para serem vistos como falantes de uma norma prestigiada, quanto para sofrerem estigmatização por certos usos da língua. Isso ocorre porque há uma pressão em todos os grupos sociais, no ambiente escolar, de trabalho, entre amigos, etc., levando o falante a adequar-se ao contexto linguístico em que se encontra. Analisar essa variável social é de suma importância, pois "o nível educativo dos falantes determina de forma direta e clara a variação linguística: é normal que as pessoas mais instruídas façam maior uso das variantes que são consideradas como mais prestigiadas, o que mais se ajustam à norma” (MORENO-FERNÁNDEZ, 1998).

Os dados levantados de objeto nulo no corpus do PEPP com relação ao objeto nulo foram:

\begin{tabular}{|c|c|c|}
\hline Faixas & Ocorrências & Porcentagem \\
\hline Fundamental & $108 / 255$ & $42 \%$ \\
\hline Médio & $147 / 255$ & $58 \%$ \\
\hline
\end{tabular}

Tabela 3: Dados relativos à faixa diastrática

Os dados da tabela 3 reforçam o que Moreno-Fernández (1998) aponta a respeito das pessoas mais instruídas apresentarem maior uso das variantes que são consideradas como mais prestigiosas, que seria o uso do $\mathrm{ON}$ no $\mathrm{PB}$ para não usar uma forma menos prestigiada que é o uso dos pronomes lexicais, como aponta Côrrea (1992). Ainda assim, os dados não estão tão distantes entre os níveis fundamental e médio, em razão de o uso do ON não ser estigmatizado, pelo contrário, ser uma estratégia para não usar formas estigmatizadas socialmente.

O gráfico 3 mostra que há uma aproximação entre os níveis, podendo o nível universitário apresentar dados relevantes, mas tal nível não faz parte do PEPP. 


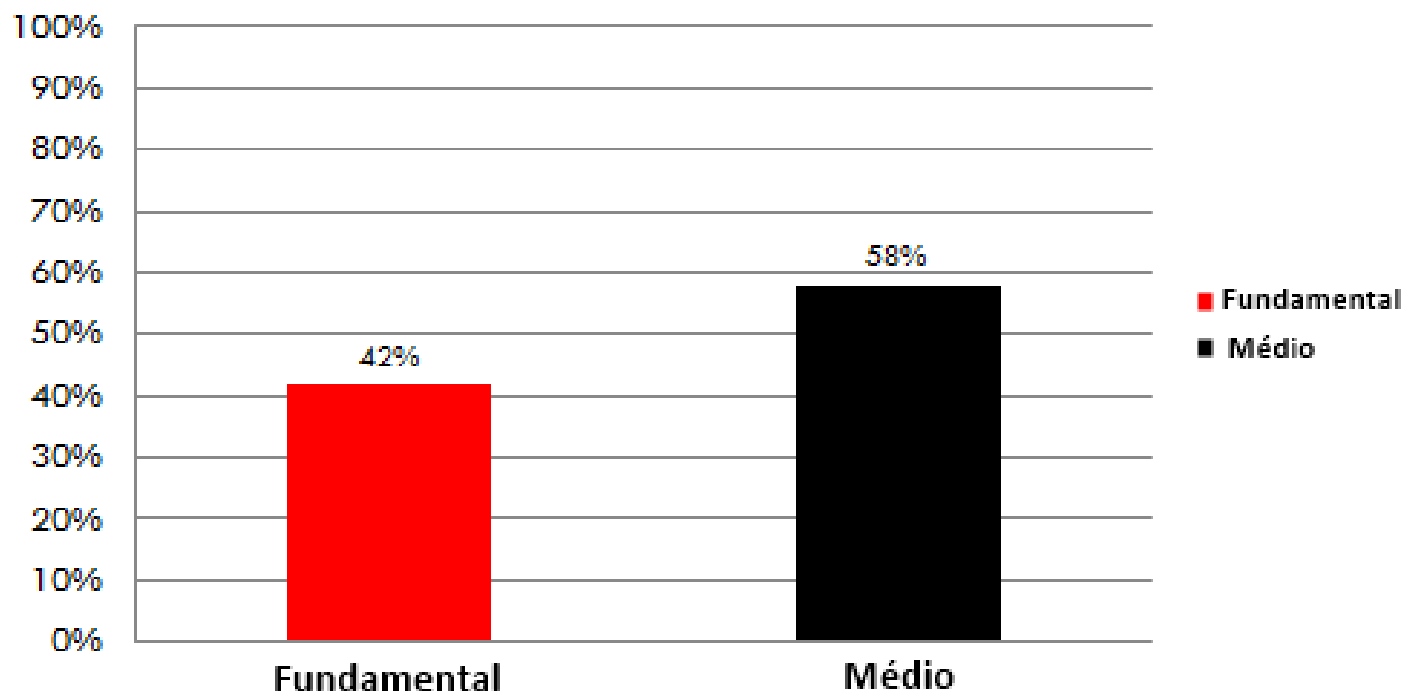

Gráfico 3: Dados relativos à variável diastrática

É perceptível que, no gráfico 3, a variável diastrática não apresenta resultados categóricos, mas revela que falantes com o nível do ensino médio $(58 \%)$ utilizam mais o ON do que os falantes com nível de instrução fundamental. Os falantes com nível de instrução fundamental $(42 \%)$ se aproximam dos falantes de ensino médio, provavelmente, por conta do crescimento de categorias vazias no PB, por essa ser uma língua intermediária de tópico-comentário (PONTES, 1987). O exemplo abaixo mostra como o ON é recuperado discursivamente:

\section{INQ12_MULHER_MÉDIO_F1}

DOC: Você guarda ainda seus BRINQUEDOS?

12MM1: Ah! Guardo BRINQUEDOS sim, tenho todas as bonecas lá guardada, todas, tanto eu como a minha irmã, todas, brinquedo não, mas a gente teve um negócio aí de um hospital, minha mãe, eu esqueci agora, a gente veio e doou todos os brinquedos né, brinquedos assim, mas boneca não, as bonecas eram tudo lá guardadas no armário, tudo de saco, de vez em quando a gente tira OS VESTIDOS, que as vezes fica com...

DOC: Cheirando.

12MM1: É, cheirando né, a gente vem e tira OS VESTIDOS , e lava OS VESTIDOS , depois veste OS VESTIDOS de novo, penteia o cabelo, eu tenho o maior carinho, e de brincadeira assim de rua, eu não andava muito na rua, sempre minha mãe né, nunca criou os filhos dela, as filhas dela sempre dentro de casa, mas de vez em quando de tardinha, dia de sábado, assim depois de fazer o exercício descia com as meninas, mas era brincadeira de esconde-esconde, de baleou, nada pesado, agora a minha irmã quando ia pra casa de minha avó, subia na casa e fica empinando arraia, era ela com os meus dois outros primos, mas eu nunca fui de empinar de arraia, nada dessas brincadeiras de masculinas. 
O falante em questão não repete os sintagmas nominais - os vestidos -, porque não é permitido na língua por serem repetições de um mesmo valor. A outra estratégia é o uso do clítico acusativo, que por não fazer mais parte da gramática do $\mathrm{PB}$, tornando-se muito formal, a falante utiliza a terceira estratégia, o uso da categoria vazia, que não é estigmatizada.

\subsection{VARIÁVEL DIASSEXUAL}

O fator sexo é extremamente relevante de se observar, principalmente na atualidade, pois houve mudanças sociais significativas que não distanciam as relações sociais de homens e mulheres de formas tão estanques. Segundo Moreno-Fernández (1998), as pesquisas sociolinguísticas de centros urbanos têm descoberto e descrito uma série de feitos relevantes sobre o sexo como variante social. Sem dúvida, o mais importante de todos eles é que a mulher, geralmente, é mais sensível às normas prestigiosas do que os homens.

Os dados de $\mathrm{ON}$, no corpus do PEPP, em relação à variável diassexual foram registrados, como apresentados na tabela 4:

\begin{tabular}{|c|c|c|}
\hline Faixas & Ocorrências & Porcentagem \\
\hline Homem & $134 / 255$ & $53 \%$ \\
\hline Mulher & $121 / 255$ & $47 \%$ \\
\hline
\end{tabular}

Tabela 4: Dados relativos à variável diassexual

A tabela 4 mostra que os dados concernentes às ocorrências de $\mathrm{ON}$ entre homens $(53 \%)$ e mulheres $(47 \%)$ não são tão distantes, como mostra o gráfico 4:

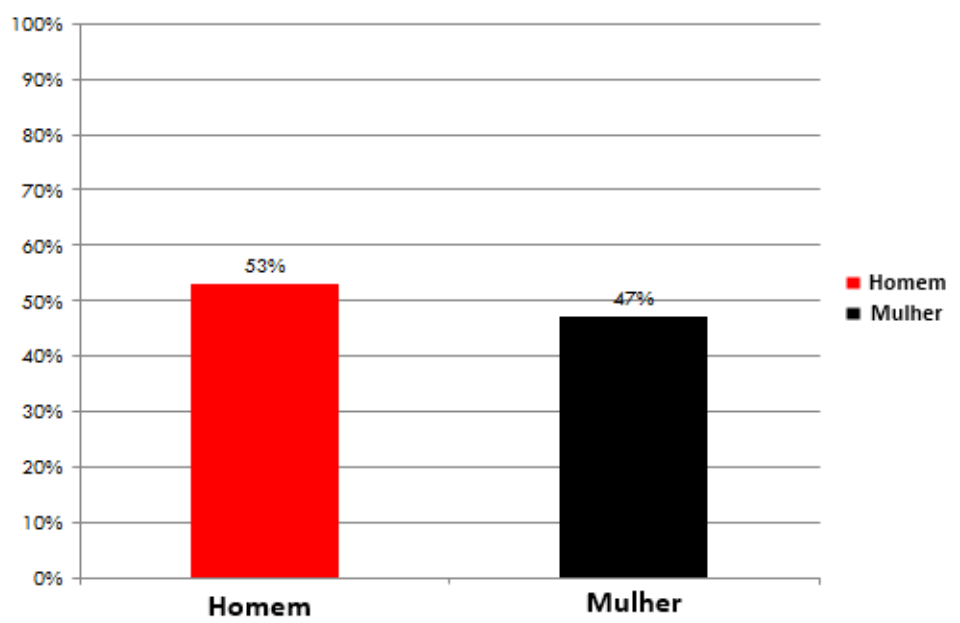

Gráfico 4: Dados relativos à variável diassexual 
Retomando Moreno-Fernández (1998), “a mulher, geralmente, é mais sensível às normas prestigiosas do que os homens", e os dados obtidos apontam o contrário. No entanto, o uso de $\mathrm{ON}$ no $\mathrm{PB}$ não revela de forma direta um tipo de prestígio linguístico, mas sim uma estratégia para fugir tanto do recurso de prestígio - uso do clítico acusativo -, quanto do recurso de baixo prestígio - uso do pronome lexical.

\section{CONSIDERAÇÕES FINAIS}

O estudo aqui empreendido nos leva às seguintes considerações com relação à variável linguística selecionada: o traço de animacidade no PB não é restrito, quanto o é em línguas como o PE, que nos poucos casos de objeto nulo, esse possui um único traço de animacidade - o [- animado] -, em outras palavras, o PB encontra-se num estágio misto, de variação linguística com relação ao uso da estratégia de ON com correferência tanto [- animada], quanto com [+ animada]. Além desse fator, vale lembrar que a análise levou em consideração objetos nulos como propostos por Silva (2009) e Valverde-Hübner (2012), diferenciando os objetos nulos das elipses de todo o sintagma verbal, conhecido na literatura como elipse de VP. Essa distinção é bastante relevante, uma vez que são fenômenos diferentes nas línguas.

No que tange às variáveis sociais: (i) a estratégia de uso da categoria vazia na posição de objeto segue os estudos diacrônicos de um uso crescente no $\mathrm{PB}$, mas não houve uso considerável dessa estratégia com relação às variáveis sociais; (ii) o uso de objeto nulo no $\mathrm{PB}$, pelo menos com relação ao corpus analisado, não foi significativa na variável diageracional, pois os dados apresentados mostram porcentagens próximas, embora a faixa I tenha se destacado, mas isso pode ter ocorrido devido ao grande número de ocorrências em dois entrevistados e outros dois com baixa ocorrência, o que poderia ser resolvido com o uso de programas estatísticos; (iii) a variável diastrática revela que as pressões de grupos sociais implicam o uso do ON, mas a diferença entre os níveis estudados é pequena ; e (iv) a variável diassexual mostra que as mudanças sociais nas relações entre homens e mulheres não apresentaram dados relevantes, já que ambos ingressaram em meios como o ambiente de trabalho e a sociabilização fora de casa.

O fenômeno observado é muito interessante e merece estudos mais aprofundados, com a expansão do corpus, para verificar se há maior relevância dos dados nas variáveis selecionadas; a seleção de outro corpus com informantes com nível universitário; a inclusão dos objetos oracionais; e a utilização de um programa estatístico para cruzar os dados com diversos fatores, impedindo problemas metodológicos e trazendo os pesos relativos, que são necessários para análises da sociolingüística quantitativa. 


\section{REFERÊNCIAS}

CHOMSKY, NOAM. Lectures on Government and Binding. Dordrecht: Foris, 1981.

CORRÊA, Vilma Reche. O objetivo direto nulo no portugues do Brasil. Dissertação de Mestrado, UNICAMP, SP, 1992.

CYRINO, Sonia Maria Lazzarini. O objeto direto nulo no português brasileiro. In: Eberhard Gärtner, Crhistine Hundte Axel Schönberger (orgs). Estudos de gramática portuguesa. V. 3, Frankfurt am Main, TFM, 2000, p. 61-73.

CYRINO, Sonia Maria Lazzarini. Algumas questões sobre a elipse de VP e objeto nulo em PB e PE .In Guedes, M; Berlinck, R. de A.; Murakawa, C. de A.A. (orgs.) Teoria e análise lingüisticas: novas trilhas. Araraquara: Laboratório Editorial FCL/UNESP,SP, Cultura Acadêmica, 2006, p. 53-79.

DUARTE, Maria Eugênia L.V ariação e sintaxe: clítico acusativo, pronome lexical e categoria važia no português do Brasil. Dissertação de mestrado, PUC-SP, 1986.

DUARTE, Sonia Maria Lazzarini. Clítico acusativo, pronome lexical e categoria vazia no português do Brasil. In: Fernando Tarallo (Org.). Fotografias Sociolingüísitcas, 1989.

GALVES, Charlotte Chambelland. Objet null et structure de la position en portugais brésilien. Revue dês langues romanes 93, 1989. p. 305-336

LOPES, Norma da Silva; SOUZA, Emília Helena Portella Monteiro de; SOUZA, Constância Maria Borges de (Org.). Um estudo da fala popular de Salvador: PEPP Salvador: Quarteto, 2009, 376p.

MATOS, Maria Gabriela Ardisson Pereira de. Construções de elipse de predicado em português SV nulo e despojamento. tese de doutorado, Universidade de Lisboa, 1992.

MORENO FERNÁNDEZ, Francisco. Principios de sociolingüística y sociología del lenguaje. Barcelona: Editora Ariel, 1998, p. 33-69

PONTES, Eunice. O tópico no português do Brasil. Campinas: Pontes, 1987. p. 11-40

RAPOSO, Eduardo. On the null subject in European Portuguese. In: JAELLI, Oswaldo; CORVALÁN, Carmen Silva. Studies in Romance Linguistics. Dordrecht: Foris, 1986. p. 370390

ROBERTS, Ian. A generalização de Taraldsen e a mudança linguística: dois modos de perder sujeitos nulos. In: TORRES MORAIS; Maria Lucia da C.de O. Andrade (Org.) . História do Português Paulista Série Estudos. V. II. 1. ed. Campinas: IEL Publicações, 2009. p . 27-59 
SILVA, Maria Cristina Vieira de Figueiredo. O objeto nulo no português rural baiano: teoria temática e elipse de DP. 2009. 189f. Tese de doutorado (Doutorado em Letras em Linguística) - Instituto de Letras da Universidade Federal da Bahia, Salvador.

TARALLO, Fernando. A pesquisa sociolinguística. São Paulo: Ática, 1986. 96 p.

VALVERDE-HÜBNER, Mirna Sodré. Em busca de uma caracteriqação para o objeto nulo no português brasileiro. Dissertação de Mestrado, Unb, Brasília, 2012, p. 32-63.

Recebido em: 02/05/2017

Aprovado em: 08/08/2017

Publicado em: 01/12/2017 